\title{
Cognitive thought diary in supportive psychology for people undergoing radiotherapy: a feasibility study
}

\author{
Giovanna MARRAZZO ${ }^{1}$, Laura FERRARO ${ }^{2} *$, Clara MEO ${ }^{3}$, Lucia SIDELI ${ }^{2}$, \\ Alice MULÈ ${ }^{1}$, Caterina LA CASCIA ${ }^{2}$, Veronica CAPUCCIO ${ }^{4}$, Anna M. MARINARO ${ }^{2}$, \\ Rosalinda RIZZO 2, Nadia VALENZIANO 2, Oriana LUPO 2, Giovanna ALAIMO 2, \\ Claudia MICELI 2, Daniela MEDUSA 2, Ivan FAZIO 5, Daniele LA BARBERA 2
}

${ }^{1}$ Department of Psychiatry, "Paolo Giaccone" University Policlinic, Palermo, Italy; ${ }^{2}$ Department of Experimental Biomedicine and Clinical Neurosciences (BIONEC), University of Palermo, Palermo, Italy; ${ }^{3}$ LILT (Lega Italiana Lotta ai Tumori), Pisa, Italy; ${ }^{4}$ Department of Economics, Business and Statistics (SEAS), University of Palermo, Palermo, Italy; ${ }^{5}$ Macchiarella Nursing Home, Palermo, Italy

*Corresponding author: Laura Ferraro, Via Gaetano La Loggia 1, 90129 Palermo, Italy. E-mail: laura.ferraro@unipa.it

\section{A B S T R A C T}

BACKGROUND: Radiation therapy (RT) has become one of the most widely-used and efficient treatments for cancer; nevertheless, people who undergo radiotherapy suffer the physical and psychological consequences of this stressful treatment, in addition to the psychosocial distress related to cancer. However, a Radiotherapy Unit is often a place where several patients crowd in from various hospitals with restricted timetables and, for logistic reasons, it is not easy to provide regular psychological sessions for each one. It is important to find a setting that allows us the involvement of the largest number of patients referred to the unit. In this study, we aimed to evaluate the feasibility and the effect of a brief intervention of cognitive-oriented diary on the quality of life, anxiety and depressive symptoms of patients undergoing radiotherapy (RT), compared to a control group.

METHODS: The sample was constituted of 68 experimental subjects and 78 controls, treated with RT. Both groups were assessed with the Toronto Alexithymia Scale (TAS-20), the Hamilton Anxiety and Depression Scale (HADS) and the EORTC-QLQ at the beginning and at the end of their RT. Experimental subjects were instructed to report emotions and thoughts before attending the RT sessions in a thought diary.

RESULTS: The experimental group showed a good adherence to the diary, a reduction in mean scores of anxiety $(\mathrm{P}<0.001)$, depression $(\mathrm{P}<0.001)$, and alexithymia $(\mathrm{P}<0.001)$ together with an ameliorative effect on quality of life $(\mathrm{P}<0.014)$, compared to control group.

CONCLUSIONS: We observed a reduction in alexithymia scores in the experimental group, together with a significant reduction in anxiety and depression symptoms and an improvement in quality of life, with a moderator role of social disparity in treatment adherence. Our outcomes suggest the opportunity to consider the diary an affordable and effective device for psychologists operating in RT units, able to be extended to the majority of patients, in a simple and replicable setting.

(Cite this article as: Marrazzo G, Ferraro L, Meo C, Sideli L, Mulè A, La Cascia C, et al. Cognitive thought diary in supportive psychology for people undergoing radiotherapy: a feasibility study. Minerva Psichiatr 2017;58:1-9. DOI: 10.23736/ S0391-1772.17.01916-1)

Key words: Psychology - Diaries - Feasibility Studies - Radiation oncology.

$\mathrm{R}$ adiation therapy (RT) has become one of the most widely-used and efficient treatments for cancer, since new technology has increased the possibility of focusing on the cancer cells by minimizing the side effects. Nevertheless, people who undergo radio- 


\section{COPYRIGHT ${ }^{\odot} 2017$ EDIZIONI MINERVA MEDICA}

therapy suffer the physical and psychological consequences of this stressful treatment, in addition to the psychosocial distress related to cancer.

A number of studies observed an increase in anxiety and other psychological complications before and after the RT treatment ${ }^{1-3}$ together with a poorer quality of life..$^{4,5} \mathrm{~A}$ recent systematic review of these studies has estimated that, before the beginning of RT treatment, anxiety was the most prevalent symptom among patients, followed by depression, but after treatment, depression remained at a higher level than anxiety. ${ }^{6}$ This suggests a stressful role of radiotherapy in itself 7 related to irrational fears of physical harm and death. ${ }^{8}$

Several studies had demonstrated the reduction in manifestations of distress in patients receiving individual psychotherapy 9-12 and supportive-expressive group therapy ${ }^{13}, 14$ when compared with the control group. Other studies indicated a positive impact of relaxation therapy sessions 15 and nurse-or therapist-led self-care and education to the treatment. ${ }^{16-18}$

The variety of interventions that have resulted effective, sometimes without any significant differences between psychotherapy and supportive interventions ${ }^{12,14}$ seem to suggest that "doing something is better than nothing". However, a Radiotherapy Unit is often a place where several patients crowd in from various hospitals with restricted timetables and, for logistic reasons, it is not easy to provide regular psychological sessions for each one.

Given that, it is important to find a setting that allows us the involvement of the largest number of patients referred to the unit. For example, Krischer et al. ${ }^{19}$ experimented selfadministered stress management training on a large sample of patients selected from multiple countries; this resulted effective only in those patients with initially higher levels of psychological distress. 20 They proposed this kind of support as a cheaper and more accessible intervention, on the basis of Jacobsen's et al. study. ${ }^{21}$

Therefore, we designed this feasibility case/ control study to test the efficacy of a simpli- fied thought-diary, based on cognitive therapy theory, in order to improve patients' conditions into a psychological supportive setting, during the intensive period of RT.

\section{Materials and methods}

\section{Participants and procedures}

The sample was constituted of patients undergoing radiotherapy for different types of cancer, stage of disease and therapies, treated at the Radiotherapy Department of the "Macchiarella Nursing Home" in Palermo (a private hospital part of the Italian National Health Insurance System) and at the Radiotherapy Department of the University Hospital of Pisa (a public hospital) from October 2012 until August 2014. Eligibility criteria for the study were: to be in a curative RT treatment (not palliative), to be aged 18-65 years and to be free of psychiatric drug therapy or psychotherapy. The study project was preliminarily authorized in its procedural and ethical contents by a panel of expert of the "Macchiarella Nursing Home".

\section{Enrollment (T0)}

The enrolment of the patients took place at the time of the "radiation simulation". At this moment, socio-demographic and Toronto Alexithymia Scale (TAS-20) 22 were administered to patients that agreed to be enrolled and with signed an informed consent.

\section{Randomization}

We used a random allocation rule, in order to obtain two numerically balanced groups. First of all, researchers undertook the patient enrolment, giving some days of availability of their radiotherapy unit. Then, a half of the researchers were assigned to the recruitment, assessment and support of the experimental group and the remaining ones to the recruitment and assessment of the control group. Both intervention researchers and control researchers were available for an equal number 
of days. The allocation of the patients to the groups was based on researcher's availability at the first session of patient's RT treatment.

\section{First assessment (T1)}

Each researcher met a patient and performed the assessment with the Hospital Anxiety and Depression Scale (HADS) 23 and EORTC-QLQ 24 in the context of a psychological supportive setting by establishing a face to face relationship. Researchers in the control group said to the patients that they would see again each other at the last session of RT in order to complete the tests again. Researchers in the experimental group presented the diary to the patients by explaining the effect of thoughts on emotions and behavior. They gave instructions about how and when to fill in the pages and completed together with the patients the first page of the diary, just helping them with the individuation of the thoughts and with the rating of the emotions. At the end of this session, researchers in the experimental group gave an appointment to the patients in order to revise the diary together, in about the middle part of the RT treatment (about 12 days later). All patients, both in experimental and in control group, received instructions and performed the assessment into a psychologically supportive setting.

\section{Diary revision}

During this intermediate psychological meeting, the patients had the opportunity to share with the psychologist what they had noticed about their feelings and thoughts trough a shared reading of the pages filled in. On this occasion, the psychologists discussed with the patients about their thoughts in relation to their negative emotions.

\section{Last assessment (T2)}

During the T2, at the last session of RT treatment, both groups were assessed again about 20-25 days after T0, with TAS-20, HADS and EORTC-QLQ. The patients in the experimen- tal group delivered the diary and this was read with the therapist.

\section{Researchers}

Reliability meetings among researchers were planned periodically in order to monitor their fidelity to the method. We have chosen to keep a one-to-one researcher-patient relationship all the time, despite its potential for introducing bias in the final assessment, because the final goal was to test the diary functioning into a psychologically supportive setting and this was the most naturalistic-like situation. Researchers in both groups provided patients with emotional support during the first and the last interview, the only difference between the groups was represented by the introduction of the diary and the intermediate interview.

\section{Statistical analysis}

To compare socio-demographic characteristics between experimental and control group a Univariate Analysis was performed using $t$-test or Welch test for quantitative variables and Pearson $\chi^{2}$ test or Fisher's exact test for qualitative variables. To control differences between Palermo and Pisa in terms of clinical characteristics, an analysis of covariance was computed using sex, age, group (experimental/ control), occupational status and education as independent variables.

Furthermore Poisson regression (forwardstepwise selection) for experimental group was calculated to investigate the main characteristics affecting the adherence to the diary (expressed as the discrete number of pages of the diary).

Analysis of covariance (ANCOVA) was performed to compare clinical scales between the two groups at the end of the treatment adjusting for baseline value. Gender, age, study center (Pisa/Palermo) occupational status and education were used as covariates. $\mathrm{P}$ value $<0.05$ were considered statistically significant and all statistical analyses were conducted using SPSS 19 software (IBM Corporation).

Different instruments were used, as described below. 


\section{COPYRIGHT ${ }^{\odot} 2017$ EDIZIONI MINERVA MEDICA}

\section{SOCIO-DEMOGRAPHIC SHEET}

It was used to collect information about gender, age, marital status, education and occupation.

\section{TAS-20}

The TAS-20 22 is a 5-point Likert Scale consisting of 20 items. It provides information on three dimensions: 1) difficulty identifying feelings (F1); 2) difficulty describing feelings (F2); 3) externally oriented thinking (F3). The TAS 20 has been widely used in a number of similar studies as a valid scale to assess the capability to identifying emotions.

\section{HADS}

The HADS 23 is a self-completing questionnaire. It is made of two scales, each including 7 items, one scale related to generalized anxiety and the other one to depression. The normative data, classify scores less than or equal to 7 as normal. The specificity of the scale is not including the somatic symptoms that typically accompany both to anxiety and depression, in order to avoid overlapping with somatic symptoms.

\section{EORTC-QLQ-C30}

The EORTC-QLQ-C30 24 is a self-administering questionnaire used to assess the quality of life in cancer patients. It investigates the stage of the illness through nine multi-item scales and a global health status scale. It includes six single-item scales investigating the presence of symptoms typically associated with cancer and some items inquiring sexuality.

\section{THE DIARY}

Subjects allocated to the experimental group were asked to briefly answer to two questions: "What am I thinking, at this moment?" And "How am I feeling, in this moment?". In the second part of the sheet, the diary indicates the following instructions: "Now we ask you to attribute a score from 1 to 10 to the following emotions, according to the intensity which you are feeling the emotion itself" and then are indicated five emotions: anxiety, sadness, fear, anger, and anguish. This is, essentially, a simplified version of a typical cognitive "though diary" that aims to emphasize the link between thoughts, feelings and behavior. Participants allocated to the experimental group were trained during the first session and were expected to fill-in one page for each day of RT, while they were sitting waiting for the RT session. They were instructed to write everything they were thinking about, even if neutral and not linked to the illness or the situation (for example "I am thinking that I have to go to the supermarket"- "I feel well").

\section{Results}

At the beginning 196 patients were involved, but 146 completed the protocol $(29.1 \%$ dropped-out), 68 experimental subjects and 78 controls (Figure 1). We collected data from two different units of radiotherapy: Palermo (76 subjects) and Pisa (70 subjects).

\section{Baseline characteristics}

The mean age of the sample was $51.1 \pm 10.8$ years but the experimental group showed a lower mean age than the control group $(\mathrm{t}=0.9$, $\mathrm{df}=144, \mathrm{P}=0.040$ ). The $75.3 \%$ of the whole sample was constituted of females, with a greater percentage of them in the experimental group $\left(\chi^{2}=4.9, \mathrm{df}=1, \mathrm{P}=0.026\right)$. The baseline profile of patients were: occupied $(54.2 \%)$, with diploma (37.1\%) and married (75.4\%), without differences between cases and controls (all $\mathrm{P}>0.05$ ). There were no differences between the experimental and the control group at the baseline in alexithymia scores (total score, F1, F2, F3) anxiety, depression and quality of life scores (all $\mathrm{P}>0.05$ ). $46.6 \%$ of the sample suffered of breast cancer, followed by rectal cancer (12.3\%), uterine cancer $(9.6 \%)$, and minor percentages of other cancers $(31.5 \%)$. 


\section{COPYRIGHT $^{\circledR} 2017$ EDIZIONI MINERVA MEDICA}

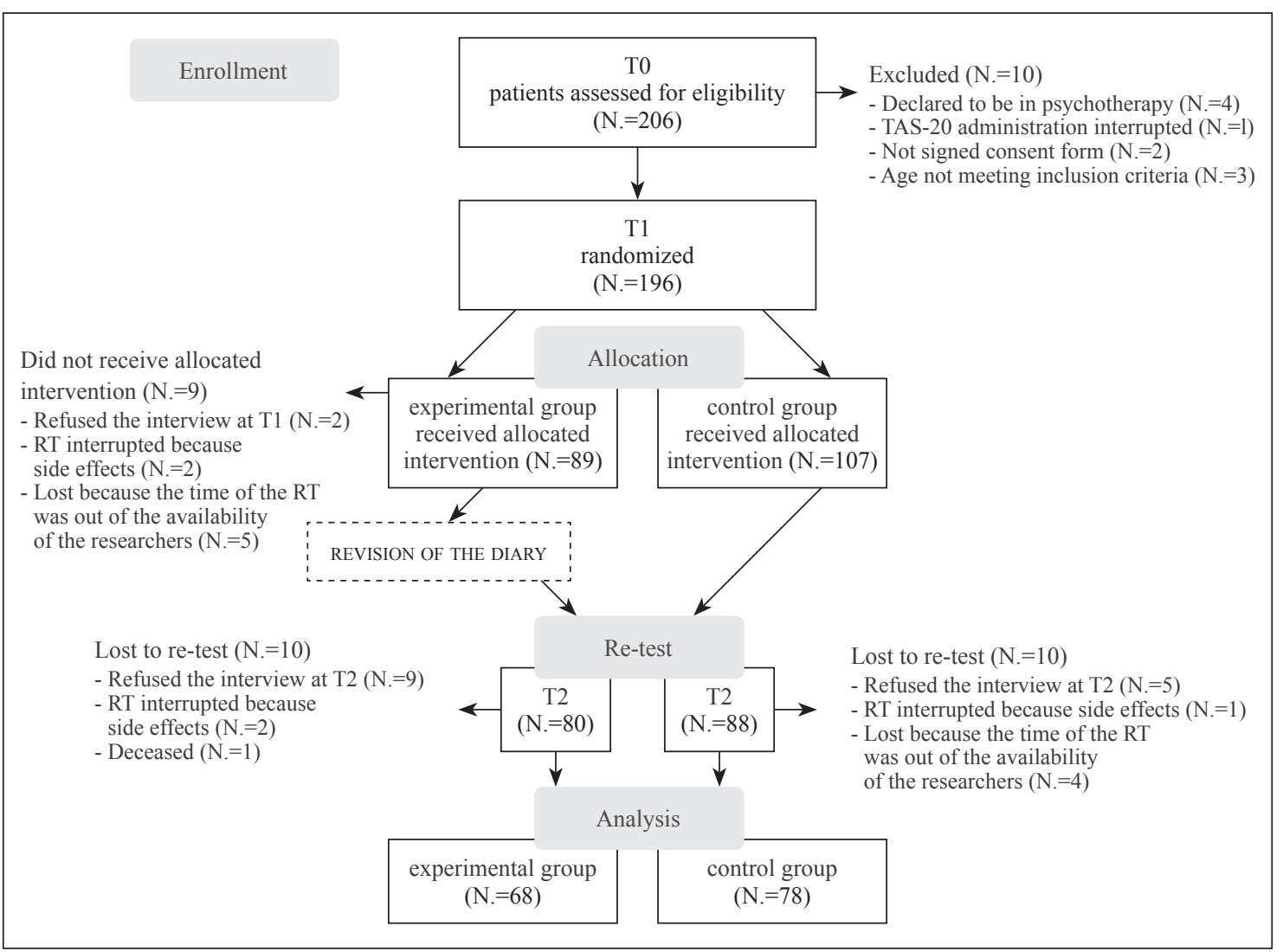

Figure 1.-Flowchart of the recruitment and assessment.

The flowchart indicates the phases of the recruitment and assessment of the subjects, from the start to the end, for both sites, with numbers of patients included and excluded and why.

T0: contact with the patient at the "radiation simulation time"; T1: first assessment time; T2. last assessment time.

\section{Sample characteristics by study center}

Table I describes the socio-demographic and clinical characteristics of the sample at the baseline by comparing the two centers. Pisa participants were younger $(\mathrm{t}=2.9, \mathrm{df}=144$, $\mathrm{P}=0.004)$; they were 1.7 times more likely to be occupied (95\% CI: 1.2-2.4) and higher edu-

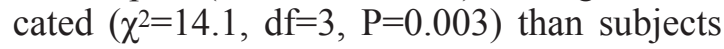
from Palermo center. Regarding the clinical characteristics at baseline the two groups showed similar level of anxiety, depression and quality of life (all $\mathrm{P}>0.05$ ). Palermo participants showed higher level of alexythimia than people from Pisa $(\mathrm{P}=0.008)$ particularly in the $\mathrm{F} 1$ subscale $(\mathrm{P}=0.007)$, that stayed significant after adjusted for age, sex, group (experimental/control), occupational status and education $(\mathrm{P}=0.031)$.

\section{Adherence to the diary}

Our experimental group completed a mean of $15.1 \pm 9.3$ pages of the assigned diary in about a mean of $25.9 \pm 8.1$ between the T1 and the T2. In order to explore which subjects' characteristics affected the adherence, we performed Poisson regression with " $\mathrm{N}$. of pages of the diary" as dependent variable and age, gender, education, occupation, marital status and alexithymia at baseline as independent variables. We performed a stepwise selection (backward and forward), the final model included the center and education variables (TRV=65.67, $\mathrm{P}<0.001)$. The interaction effect between center and education variables was not included in the analysis because the paucity of the sample.

Using patient with high school degree as 


\section{COPYRIGHT ${ }^{\odot} 2017$ EDIZIONI MINERVA MEDICA}

TABLE I.-Socio-demographic and clinical characteristic of the sample at the baseline by comparing Pisa and Palermo centers.

\begin{tabular}{|c|c|c|c|c|}
\hline & Pisa $(\mathrm{N} .=70)$ & Palermo $(\mathrm{N} .=76)$ & $P$ value & Adjusted $P$ value $*$ \\
\hline \multicolumn{5}{|l|}{ Socio-demographic characteristic } \\
\hline \multicolumn{5}{|l|}{ Gender } \\
\hline Females, N. (\%) & $57(81.4)$ & $53(69.7)$ & \multirow{2}{*}{0.102} & \multirow[t]{2}{*}{ NA } \\
\hline Males, N. (\%) & $13(18.6)$ & $23(30.3)$ & & \\
\hline Age mean (SD) & $48.5(10.3)$ & $53.6(10.6)$ & $0.004 *$ & NA \\
\hline \multicolumn{5}{|l|}{ Occupational status } \\
\hline Occupied, N. (\%) & $48(68.6)$ & $30(40.5)$ & \multirow[t]{2}{*}{$0.001 *$} & \multirow{2}{*}{ NA } \\
\hline Unoccupied, N. (\%) & $22(31.4)$ & $44(59.5)$ & & \\
\hline \multicolumn{5}{|l|}{ Education } \\
\hline Primary school, N. (\%) & $4(5.7)$ & $20(27.4)$ & \multirow[t]{4}{*}{$0.003 *$} & \multirow[t]{4}{*}{ NA } \\
\hline Middle school, N. (\%) & $19(27.1)$ & $21(28.8)$ & & \\
\hline Diploma, N. (\%) & $30(42.9)$ & $23(31.5)$ & & \\
\hline Degree, N. $(\%)$ & $17(24.3)$ & $9(12.3)$ & & \\
\hline \multicolumn{5}{|l|}{ Marital status } \\
\hline Single, N. (\%) & $15(21.4)$ & $6(8.3)$ & \multirow[t]{4}{*}{0.057} & \multirow[t]{4}{*}{ NA } \\
\hline Married, N. (\%) & $48(68.6)$ & $59(81.9)$ & & \\
\hline Divorced, N. (\%) & $5(7.1)$ & $2(2.8)$ & & \\
\hline Widowed, N. (\%) & $2(2.9)$ & $5(6.9)$ & & \\
\hline \multicolumn{5}{|l|}{ Clinical characteristic } \\
\hline Anxiety (HADS) T1 mean (SD) & $6.9(4.7)$ & $7.7(4.9)$ & 0.328 & 0.689 \\
\hline Depression (HADS) T1 mean (SD) & $5.7(4.5)$ & $6.3(4.7)$ & 0.393 & 0.868 \\
\hline Quality of life (EORTC-QLQ-C30) T1 mean (SD) & $67.0(18.4)$ & $68.0(24.9)$ & 0.772 & 0.592 \\
\hline \multicolumn{5}{|l|}{ Alexithymia (TAS-20) T0 } \\
\hline Total score, mean (SD) & $45.6(12.5)$ & $51.7(14.4)$ & $0.008^{*}$ & 0.141 \\
\hline Difficulty identifying feelings (F1), mean (SD) & $44.3(19.7)$ & $53.9(22.1)$ & $0.007 *$ & $0.031 *$ \\
\hline Difficulty describing feelings (F2), mean (SD) & $47.9(21.5)$ & $52.3(21.3)$ & 0.211 & 0.797 \\
\hline Externally oriented thinking (F3), mean (SD) & $44.7(14.5)$ & $49.9(14.4)$ & $0.033^{*}$ & 0.398 \\
\hline
\end{tabular}

SD: standard deviation; NA: not applicable. ${ }^{¥}$ Adjusted for age, sex, group (experimental/control), occupational status and education. *Significant values.

baseline category, there was a statistically significant difference with the primary school category $(\mathrm{P}=0.013)$, and with middle school category $(\mathrm{P}<0.001)$. No statistically significant difference with diploma category was detected $(\mathrm{P}=0.422)$; that means that patient who had

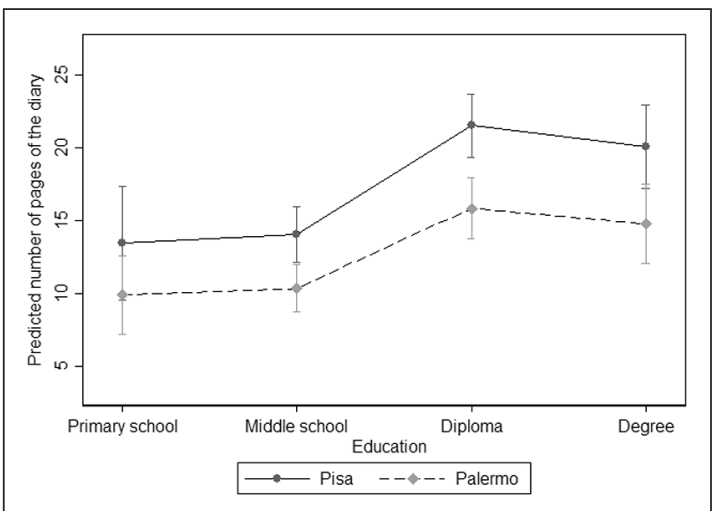

Figure 2.- Predicted number of pages of the diary in Pisa and in Palermo by Education. achieved primary or middle school diploma completed a lower number of pages than patients with high school diploma or degree (Figure 2). There was also a center effect on the adherence to the diary that was greater in Pisa than in Palermo: while in the former, the patients used the diary for an estimated mean of 18 days, in the latter group, patients spent only a mean of 13 days $(\mathrm{P}<0.001)$. In conclusion, adherence to the diary was not related to any of the others socio-demographic and clinical characteristics of the subjects, but the recruitment center and the level of education.

\section{Treatment effect}

Table II and Figure 3 describe estimated mean scores for anxiety, depression and alexythimia between cases and controls at the end of the treatment (T2) adjusting for baseline value (T1), occupational status, education, 


\section{COPYRIGHT ${ }^{\odot} 2017$ EDIZIONI MINERVA MEDICA}

COGNITIVE THOUGHT DIARY IN SUPPORTIVE PSYCHOLOGY FOR PEOPLE UNDERGOING RT

MARRAZZO

TABLE II.-Anxiety, depression, quality of life, and alexithymia scores in experimental and control subjects at the end of the treatment (T2).

\begin{tabular}{lccc}
\hline & Experimental (N.=68) & Control (N.=78) & Two-tailed P value \\
\hline Anxiety (HADS) mean (SD) & $5.4(0.37)$ & $7.6(0.34)$ & $<0.001^{*}$ \\
Depression (HADS) mean (SD) & $4.0(0.31)$ & $6.6(0.29)$ & $<0.001^{*}$ \\
Quality of life (EORTC-QLQ-C30) mean (SD) & $73.6(1.97)$ & $66.1(1.82)$ & $0.007^{*}$ \\
Alexithymia (TAS-20) Total score, mean (SD) & $41.8(1.25)$ & $50.7(1.15)$ & $<0.001^{*}$ \\
\hline
\end{tabular}

Estimated Mean \pm SE (standard error). ${ }^{¥}$ Adjusted for gender, age, study center (Pisa/Palermo), occupational status, education and baseline values (T1). *Significant values.

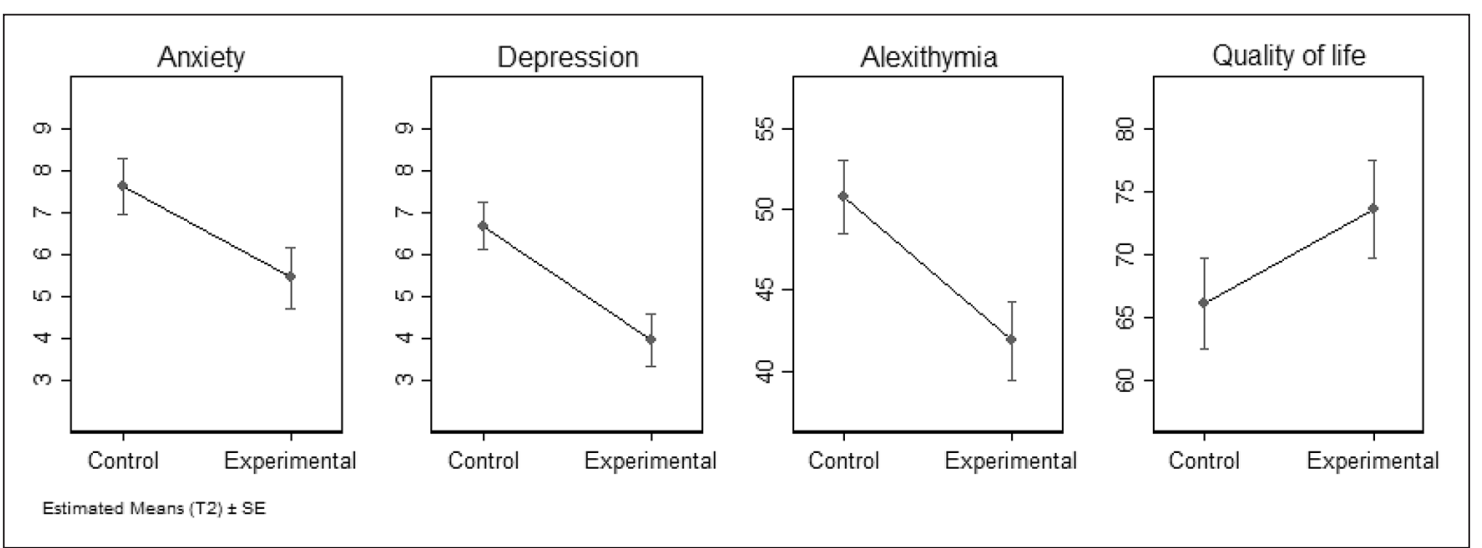

Figure 3.-Estimated mean at the end of the RT for the experimental group, adjusted for baseline mean values.

study center (Pisa/Palermo), gender and age. They both show that experimental group has significant lower scores in anxiety $(\mathrm{P}<0.001)$, depression $(\mathrm{P}<0.001)$ and alexithymia $(\mathrm{P}<0.001)$ compared to the control group together with an ameliorative effect on quality of life $(\mathrm{P}=0.007)$.

\section{Discussion}

This was a feasibility study aimed to evaluate if the introduction of a cognitive thought diary is able to reduce the stressful psychological impact in patients undergoing radiotherapy, compared to a control group.

\section{Feasibility of the diary}

The diary has been used by patients in our experimental group for more than a half of the time (i.e. 15 days on 25.9) during the course of their radiotherapy. The adherence was greater in patients with a higher level of education, as is generally the case for adherence in thera- pies. More of $60 \%$ of the sample from Pisa was occupied compared to the $30 \%$ of Palermo sample and patients from Pisa achieved a higher educational status, thus indicating a higher socio-economic status. ${ }^{25}$ As expected, the difference in level of education resulted related to the alexithymia score, 26 higher in people from Palermo than in people from Pisa and reflected in a lower capacity of identifying feelings. Taken together, these findings could be responsible for the differences in adherence.

As a major result, we obtained a reduction in alexithymia scores in the experimental group, especially in "difficulty describing feelings", together with a significant reduction in symptoms and an amelioration in quality of life, and this is a strength for the evaluation of the effectiveness of this instrument, as further discussed.

\section{The effectiveness of the diary}

It is well known that the diary method was already used by Freud in the 1920s for the analysis of his patients' dreams, but the most 


\section{COPYRIGHT ${ }^{\odot} 2017$ EDIZIONI MINERVA MEDICA}

influence on its use is represented by cognitive and behavioral therapy (CBT) in the 1960s. ${ }^{27}$ The diary is both an excellent method for conducting naturalistic research as a selfmonitoring method and a therapeutic method, in the context of self-control enhancing intervention methods. ${ }^{28}$ As suggested by Ilardi and Craighead, ${ }^{29}$ the sensitivity of self-monitoring instruments may empower the patient's self-efficacy, through the experience of active coping with their problems. We choose this technique for three reasons: Theoretical, practical, contingent. From a theoretical point of view, CBT has largely demonstrated how reflecting on the self-talk one has during a specific situation can facilitate identifying those thoughts that are harmful and self-defeating, while increasing the awareness on the link between these thoughts and the emotions that they generate. In the meantime, it can reduce the incommunicability of certain emotions and help to be less confused and ruminant. From a practical point of view, we needed an instrument that could be economic and replicable, able to reduce the number of psychologists involved in supportive intervention in a unit of RT, even if it is meant to be used as part of a larger professional intervention and not by a patient alone. Finally, the contingent fact that people in RT are obliged to go everyday for at least 20 days at the hospital and waiting for their RT session without nothing to do, apart from worrying and wishing to be elsewhere, suggested us that diary have could be a helpful self-help and takeat-home daily instrument, capable to enhance the efficacy of the supportive meetings whit the psychologist, by constituting a temporal link of continuity with the psychological setting.

At this stage we would like to acknowledge that our method could be over included into the field of the Expressive Writing Interventions (EWI) ${ }^{30}$ that have been largely used with cancer patients and that, despite their feasibility, have shown little or no main effects for psychological or physical outcomes. ${ }^{31}$ However, we would like to highlight the fact that our diary had very different instructions and was designed from a different theoretical point of view, in order to individuate that thoughts capable to stimulate negative emotions trough the psychologist's intervention and not only by a simple emotional disclosure.

\section{Limitations of the study}

This study was a feasibility study aimed at evaluating the effectiveness of a cheap, easily deliverable, supportive intervention to reduce the impact of RT on anxiety, depression, and quality of life. To increase generalization of these findings, the sample included patients recruited by a private hospital, part of the National run health care, and by a public hospital, who were highly heterogenic in terms of age, education, type of cancer, stage of the disease, and adjuvant therapies. Patients were randomly assigned to groups on the basis of a random allocation rule. Although this randomization method might be prone to selection bias in efficacy trials, it can be accepted in feasibility studies where units of randomization may consist in healthcare institutions or practitioners. Additionally, the dropouts rate was limited to about $30 \%$ and equally distributed across groups, suggesting that the sample is sufficiently representative of the source population. Nevertheless, this study has also several limitations: both researchers and patients were not blind to the allocation rule and the group assignment, thus increasing the risk of information bias, and differences between groups. Moreover, it cannot be excluded that the study findings were partially driven by the effect of unknown cofounding unequally distributed between groups.

\section{Conclusions}

We observed a good adherence to the diary, as a tool of support during radiotherapy into psychological support. We also obtained a reduction in alexithymia scores in the experimental group, together with a significant reduction in anxiety and depression symptoms and an amelioration in quality of life, with a moderator role of social disparity in treatment adherence. Our outcomes suggest the opportunity to consider the diary an affordable and effective device for psychologists operating in 


\section{COPYRIGHT ${ }^{\odot} 2017$ EDIZIONI MINERVA MEDICA}

COGNITIVE THOUGHT DIARY IN SUPPORTIVE PSYCHOLOGY FOR PEOPLE UNDERGOING RT

MARRAZZO

RT units, able to be extended to the majority of patients, in a simple and replicable setting.

\section{References}

1. Gottschalk LA, Kunkel R, Wohl TH, Saenger EL, Winget $\mathrm{CN}$. Total and half body irradiation. Effect on cognitive and emotional processes. Arch Gen Psychiatry 1969;21:574-80.

2. Peck A, Boland J. Emotional reactions to radiation treatment. Cancer 1977;40:180-4.

3. Maraste R, Brandt L, Olsson H, Ryde-Brandt B. Anxiety and depression in breast cancer patients at start of adjuvant radiotherapy. Relations to age and type of surgery. Acta Oncol 1992;31:641-3.

4. Wallace LM, Priestman SG, Dunn JA, Priestman TJ. The quality of life of early breast cancer patients treated by two different radiotherapy regimens. Clin Oncol 1993;5:228-33.

5. Badr H, Gupta V, Sikora A, Posner M. Psychological distress in patients and caregivers over the course of radiotherapy for head and neck Cancer. Oral Oncol2014;50:1005-11.

6. Hess CB, Chen AM. Measuring psychosocial functioning in the radiation oncology clinic: a systematic review. Psychooncology 2014;23:841-54.

7. Lamszus K, Verres R, Hübener KH. [How do patients experience radiotherapy?]. Strahlenther Onkol 1994;170:162-8 [Article in German].

8. Halkett GKB, Kristjanson LJ, Lobb EA. "If we get too close to your bones they"ll go brittle': women's initial fears about radiotherapy for early breast cancer. Psychooncology 2008;17:877-84.

9. Forester B, Kornfeld DS, Fleiss JL. Psychotherapy during radiotherapy: effects on emotional and physical distress. Am J Psychiatry 1985;142:22-7.

10. Schnur JB, David D, Kangas M, Green S, Bovbjerg DH, Montgomery GH. A randomized trial of a cognitive-behavioral therapy and hypnosis intervention on positive and negative affect during breast cancer radiotherapy. J Clin Psychol 2009;65:443-55.

11. Guo Z, Tang H-Y, Li H, Tan SK, Feng KH, Huang YC, et $a l$. The benefits of psychosocial interventions for cancer patients undergoing radiotherapy. Health Qual Life Outcomes 2013;11:121.

12. Kangas M, Milross C, Taylor A, Bryant RA. A pilot randomized controlled trial of a brief early intervention for reducing posttraumatic stress disorder, anxiety and depressive symptoms in newly diagnosed head and neck cancer patients. Psychooncology 2013;22:1665-73.

13. Forester B, Kornfeld DS, Fleiss JL, Thompson S. Group psychotherapy during radiotherapy: effects on emotional and physical distress. Am J Psychiatry 1993;150:1700-6.

14. Evans RL, Connis RT. Comparison of brief group therapies for depressed cancer patients receiving radiation treatment. Public Health Rep 1995;110:306-11.

15. Decker TW, Cline-Elsen J, Gallagher M. Relaxation therapy as an adjunct in radiation oncology. J Clin Psychol 1992;48:388-93.
16. Grant M. The effect of nursing consultation on anxiety, side effects, and self-care of patients receiving radiation therapy. Oncol Nurs Forum 1990;17(3 Suppl):31-6.

17. Wengström Y, Häggmark C, Strander H, Forsberg C. Effects of a nursing intervention on subjective distress, side effects and quality of life of breast cancer patients receiving curative radiation therapy-a randomized study. Acta Oncol 1999;38:763-70.

18. Halkett GKB, O'Connor M, Aranda S, Jefford M, Shaw $\mathrm{T}$, York $\mathrm{D}$, et al. Pilot randomised controlled trial of a radiation therapist-led educational intervention for breast cancer patients prior to commencing radiotherapy. Support Care Cancer 2013;21:1725-33.

19. Krischer MM, Xu P, Meade CD, Jacobsen PB. Self-administered stress management training in patients undergoing radiotherapy. J Clin Oncol 2007;25:4657-62.

20. Stiegelis HE, Hagedoorn M, Sanderman R, Bennenbroek FT, Buunk BP, van den Bergh AC, et al. The impact of an informational self-management intervention on the association between control and illness uncertainty before and psychological distress after radiotherapy. Psychooncology 2004;13:248-59.

21. Jacobsen PB, Meade CD, Stein KD, Chirikos TN, Small BJ, Ruckdeschel JC. Efficacy and costs of two forms of stress management training for cancer patients undergoing chemotherapy. J Clin Oncol 2002;20:2851-62.

22. Bagby RM, Taylor GJ, Parker JDA, Dickens SE. The development of the Toronto Structured Interview for Alexithymia: item selection, factor structure, reliability and concurrent validity. Psychother Psychosom 2006;75:2539.

23. Zigmond AS, Snaith RP. The hospital anxiety and depression scale. Acta Psychiatr Scand 1983;67:361-70.

24. Aaronson NK, Ahmedzai S, Bergman B, Bullinger M, Cull A, Duez NJ, et al. The European Organization for Research and Treatment of Cancer QLQ-C30: a qualityof-life instrument for use in international clinical trials in oncology. J Natl Cancer Inst 1993;85:365-76.

25. Kissane D. Beyond the psychotherapy and survival debate: the challenge of social disparity, depression and treatment adherence in psychosocial cancer care. Psychooncology 2009;18:1-5.

25. Marmot M. The influence of income on health: views of an epidemiologist. Health Aff 2002;21:31-46.

26. Lane RD, Sechrest L, Riedel R. Sociodemographic correlates of alexithymia. Compr Psychiatry 1998;39:377-85.

27. Korotitsch WJ, Nelson-Gray RO. An overview of selfmonitoring research in assessment and treatment. Psychological Assessment 1999;11:415-25.

28. Thiele C, Laireiter A-R, Baumann U. Diaries in clinical psychology and psychotherapy: a selective review. Clinical Psychology \& Psychotherapy 2002;9:1-37.

29. Ilardi SS, Craighead WE. The Role of Nonspecific Factors in Cognitive-Behavior Therapy for Depression. Clinical Psychology: Science and Practice 1994;1:138-55.

30. Pennebaker JW, Beall SK. Confronting a traumatic event: toward an understanding of inhibition and disease. J Abnorm Psychol 1986;95:274-81.

31. Zachariae R, O'Toole MS. The effect of expressive writing intervention on psychological and physical health outcomes in cancer patients-a systematic review and meta-analysis. Psychooncology 2015;24:1349-59.

Authors' contributions. - Giovanna Marrazzo and Laura Ferraro contributed equally to the article.

Conflicts of interest.-The authors certify that there is no conflict of interest with any financial organization regarding the material discussed in the manuscript.

Manuscript accepted: December 31, 2016. - Manuscript received: November 29, 2016. 